\title{
SCROTAL MASS: A RARE COMPLICATION OF VENTRICULOPERITONEAL SHUNT
}

\author{
Christopher C.K Ho, Wan Jasman Jamaludin, Eng Hong Goh, Praveen Singam, Zulkifli Md Zainuddin \\ Division of Urology, Department of Surgery, Universiti Kebangsaan Malaysia Medical Centre \\ Summary: Ventriculoperitoneal shunts are associated with multiple complications. Among them are disconnection and mi- \\ gration of the tubing into the peritoneal cavity. Here we describe a case of a fractured ventriculoperitoneal shunt which \\ migrated and coiled in the scrotum, masquerading as a scrotal swelling. Removal of the shunt via a scrotal incision was \\ performed concomitantly with repair of the hernia sac.
}

Key words: Inguinal hernia; Scrotal mass; Foreign body; Ventriculoperitoneal shunt

\section{Introduction}

Ventriculoperitoneal (VP) shunt is a common procedure in managing hydrocephalus. Complications associated with VP shunt are numerous and can be disastrous. Among the complications that can occur are migration of the catheter into the abdominal wall, gastrointestinal tract, bladder, vagina, scrotum, mediastinum and infections like peritonitis, ventriculitis, and meningitis $(24-47 \%)(5,7)$. One of the rare complications associated with ventriculoperitoneal shunt is herniation of the peritoneal catheter into the scrotum. Here we describe the migration of a fractured VP shunt catheter into the left scrotum.

\section{Case report}

A 14-year-old boy with congenital hydrocephalus on VP shunt, presented with a history of left scrotal swelling for three days associated with pain and fever. There was no previous history of epididymitis or orchitis. Examination of the scrotum revealed a $4 \times 3 \mathrm{~cm}$ mass, separate from the testis, in the scrotum. Cough impulse and transillumination test was negative. Full blood count and urine test was normal. Ultrasound done showed a foreign body in the scrotum with mild hydrocoele.

On further questioning, his mother admitted that his previous VP shunt catheter had fractured a year ago and was replaced with a new one. The shunt had then migrated into the abdominal cavity but since it was not causing any problem, his parents were not keen for any abdominal surgery. An abdominal pelvic x-ray was done and it confirmed the migration of the previously fractured VP shunt into the left scrotum (Fig. 1).
Removal of the catheter was attempted via an inguinal incision but failed. A scrotal incision had to be made to remove the catheter (Fig. 2). The hernia sac was then ligated and divided via the inguinal wound. Post operatively, he recovered well and was discharged the next day. Clinic followup at one, three and six months showed that there was no recurrence or complications.

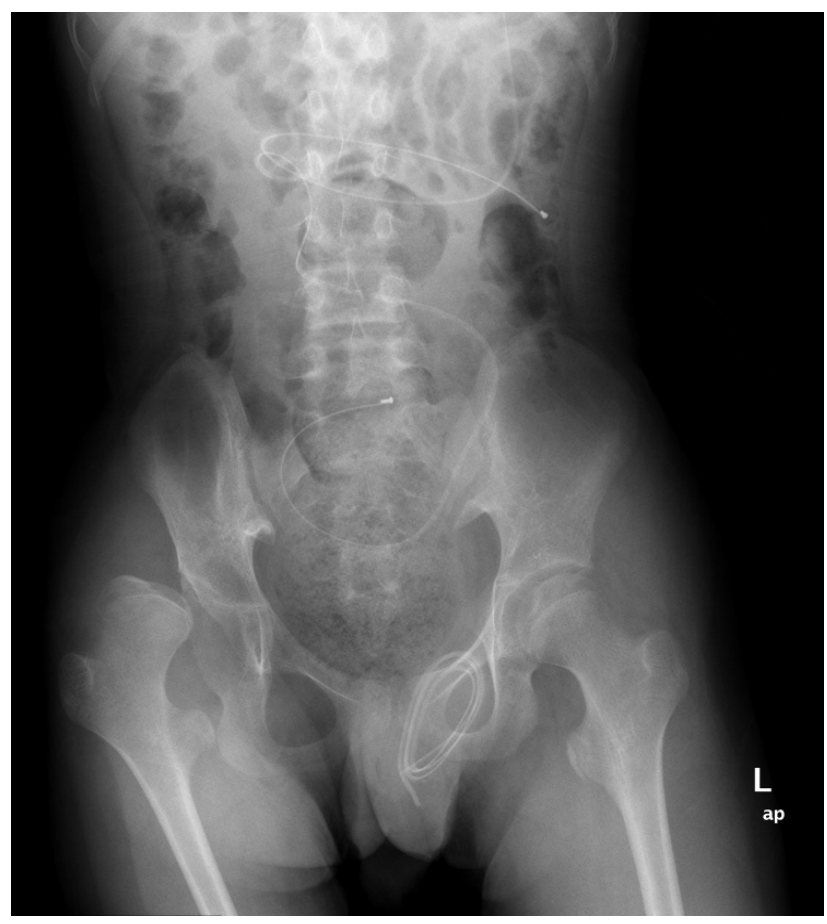

Fig. 1: Abdominal x-ray showing the fractured ventriculoperitoneal (VP) shunt catheter coiled in the scrotum. 


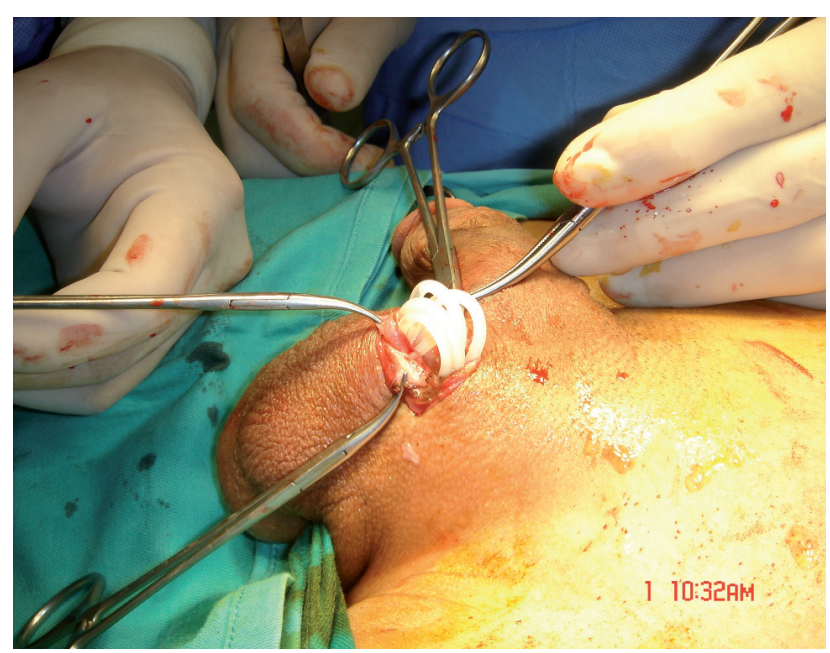

Fig. 2: Intra-operative removal of ventriculoperitoneal (VP) shunt catheter via scrotal incision.

\section{Discussion}

VP shunt is a well established modality of treatment for hydrocephalus. However, the complication rate is relatively high. It has been reported that $24 \%$ of infants and children with hydrocephalus treated by VP shunt procedures developed intra-abdominal complications. The occurrence of a previously unrecognized inguinal hernia was noted in $16.8 \%$ patients. The mean interval from VP shunt to hernia occurrence was 6.8 months (2). Other recognized complications of VP shunt (24-47 \%) are infection, perforation of the colon and bladder, intra-abdominal cerebrospinal fluid (CSF) cyst, intestinal obstruction due to volvulus and even death (7). There are also 2 reported cases of anal extrusion of distal VP shunt catheter after perforation of the large intestine $(4,7)$ and one case of a VP shunt catheter wrapped around a right mammary prosthesis forming a pseudocyst (1).

Fractured VP shunt may not need to be removed provided it is not causing any complication (6). However with a newly inserted VP shunt which is functioning well, the drainage of cerebrospinal fluid into the abdominal cavity will increase the intra-abdominal pressure. Coupled with the presence of a patent processus vaginalis, there is a risk of herniation of the previously fractured VP shunt into the scrotum because the increased intra-abdominal pressure maintains the patency of the processus vaginalis. The incidence of clinically presenting hernias is $16 \%$. If no intervention is done, there is a higher risk (20\%) of incarceration (2). Surgeons should keep this in mind if they decide to leave a fractured VP shunt in situ and not explore the abdomen. The patient and the family should be informed of the risks involved in leaving the catheter in the abdomen.

Conventionally, removal of a migrated VP shunt requires laparotomy. However, with the advent of laparoscopy, the need for laparotomy has diminished. Jackson et al. (3) has also reported his novel single- incision laparoscopic technique for removal of VP shunt tubing in the peritoneum.

\section{Conclusion}

Due to the high risk of incarceration, parents should be advised to have surgery done to remove the dislocated VP shunt in the scrotum. Surgeons too should be alert of the diagnosis of migrated VP shunt in a patient who presented with scrotal mass and has a history of VP shunt insertion.

\section{Conflict of Interest}

The authors have nothing to disclose.

\section{References}

1. Chu YT, Chuang HC, Lee HC, Cho DY. A ventriculoperitoneal shunt catheter wrapped around a right mammary prosthesis forming a pseudocyst. J Clin Neurosci 2010;17(6):801-3.

2. Grosfeld JL, Cooney DR, Smith J, Campbell RL. Intra-abdominal complications following ventriculoperitoneal shunt procedures. Pediatrics 1974;54:791-6.

3. Jackson CC, Chwals WJ, Frim DM. A single-incision laparoscopic technique for retrieval and replacement of disconnected ventriculoperitoneal shunt tubing found in the peritoneum. Pediatr Neurosurg 2002;36:175-7.

4. Jang HD, Kin MS, Lee NH, Kim SH. Anal extrusion of distal V-P shunt cathete after double perforation of large intestine. J Korean Neurosurg Soc 2007;42:232-234.

5. Kaudalka J, Patizek J. Intraabdominal complication of ventriculoperitioneal shunt in the treatment of hydrocephalus in children. Lang Czech Cesk Pediatr 1990;45(12):723-725.

6. Lee YH, Park EK, Kim DS, Choi JU, Shim KW. What should we do with a discontinued Childs Nerv Syst 2010;26:791-6.

7. Vuyyuru S, Ravuri SR, Tandra VR, Panigrahi MK. Anal extrusion of ventriculo peritoneal shunt tube: Endoscopic removal. J Pediatr Neurosci 2009;4:124-6.

Received: $16 / 08 / 2010$.

Accepted in revised form: 24/01/2011.

\section{Corresponding author:}

Christopher Ho Chee Kong, Department of Surgery, Universiti Kebangsaan Malaysia Medical Centre, Jalan Yaacob Latiff, Bandar Tun Razak, 56000 Cheras, Kuala Lumpur, Malaysia; e-mail: chrisckho2002@yahoo.com 